the current smoker group maintained a 28 day quit and 4/13 (31\%) reduced tobacco intake. Psychological barriers to quitting were identified including smoking as a means of emotion regulation.

Conclusions For COPD smokers with a heavy smoking history and multiple quit attempts, and complex needs, additional psychological intervention alongside traditional quit smoking support may aid in preventing relapse, although further research is needed. For current smokers, the hypothesis was not supported, although the study did illuminate common themes regarding obstacles to quitting for this complex group who present a challenge to traditional quit smoking services.

It is clear that the current 'one size fits all' approach to smoking cessation does not meet the needs of these smokers who require more focused specific interventions to support smoking cessation including:

- Pre-quit support

- 'Cut down to quit' approach

- Long-term, intensive follow up

- Assertive outreach

- Multi-agency working

The above recommendations may provide a starting point for future service design.

\begin{tabular}{ll} 
Abstract P286 Table 1 & Patient demographics and morbidity \\
\hline Age (mean years \pm SD) & $59 \pm 10(n=57)$ \\
M:F & $27: 32$ \\
FEV1 (mean litres $\pm S D)$ & $1.59 \pm 0.8(n=37)$ \\
MRC Dyspnoea Score (mean $\pm S D)$ & $2.28 \pm 1(n=37)$ \\
Coexisting physical health problem e.g. arthritis, diabetes & $79 \%(n=29)$ \\
Coexisting mental health problem e.g. depression, anxiety & $64 \%(n=28)$ \\
\% with at least one psychosocial issue e.g. housing problems & $67 \%(n=30)$ \\
Unemployed & $57 \%(n=35)$ \\
Pack Year History (mean $\pm S D)$ & $41 \pm 22$ \\
No. of previous quit attempts & $3 \pm 2$ \\
\hline
\end{tabular}

\section{P287 MEASURING THE ACUTE CARDIOVASCULAR EFFECTS OF SHISHA SMOKING: A CROSS-SECTIONAL STUDY}

MK Kadhum, AEJ Jaffery, AH Haq, JB Bacon, BM Madden. St. George's University of London, London, UK

\subsection{6/thoraxjnl-2014-206260.405}

Objectives To investigate the acute cardiovascular effects of smoking shisha.

Design A cross-sectional study was carried out in six shisha cafes. Participants smoked shisha for a period between $45 \mathrm{~min}$ (minimum) and 90 min (maximum). The same brand of tobacco and coal was used.

Setting London, UK.

Participants

Participants were those who had ordered a shisha to smoke and consented to have their blood pressure, heart rate and carbon monoxide levels measured. Excluded subjects were those who had smoked shisha in the previous $24 \mathrm{~h}$, who smoke cigarettes or who suffered from cardiorespiratory problems.

Main outcome measures Blood pressure was measured using a sphygmomanometer. Pulse was measured by palpation of the radial artery. Carbon monoxide levels were obtained via a carbon monoxide monitor. These indices were measured before the participants began to smoke shisha and after they finished or when the maximum 90 min time period was reached.

Results Mean arterial blood pressure increased from $96 \mathrm{mmHg}$ to $108 \mathrm{mmHg}(\mathrm{p}<0.001)$. Heart rate increased from 77 and 91 bpm $(\mathrm{p}<0.001)$. Carbon monoxide increased from an average of 3 to $35 \mathrm{ppm}(\mathrm{p}<0.001)$. A correlation analysis showed no relationship between carbon monoxide and the other indices measured.

Conclusion The acute heart rate, blood pressure and carbon monoxide levels were seen to rise significantly after smoking shisha. The weak correlation between carbon monoxide levels and the other variables suggests that carbon monoxide levels had not contributed to their significant increase.

\section{P288 THE DESENSITISATION EFFECT OF GRAPHIC HEALTH WARNING LABELS AND CROSS-CULTURAL DIFFERENCES IN THE AWARENESS OF SMOKING RELATED CONSEQUENCES: COMPARING A LONDON AND SINGAPORE COHORT}

${ }^{1} \mathrm{C}$ Ratneswaran, ${ }^{2} \mathrm{~B}$ Chisnall, ${ }^{3} \mathrm{~A}$ Douiri, ${ }^{4} \mathrm{MY} \mathrm{Li},{ }^{4} \mathrm{~S}$ Tan, ${ }^{4} \mathrm{~S}$ Tan, ${ }^{4} \mathrm{C}$ Chang, ${ }^{5} \mathrm{D}$ Anantham, ${ }^{1} \mathrm{~J}$ Steier. 'Guy's and St Thomas' NHS Foundation Trust, London, UK; 'King's College London School of Medicine, London, UK; ${ }^{3}$ Department of Public Health Sciences, King's College London andNIHR Biomedical Research Centre, London, UK; ${ }^{4}$ National University of Singapore, Singapore; ${ }^{5}$ Singapore General Hospital, Singapore

\subsection{6/thoraxjnl-2014-206260.406}

Introduction and objectives Graphic Health Warning Labels (GHWL) assist in primary and secondary smoking prevention. A lack of evidence exists regarding their desensitisation with increased exposure. Investigating knowledge and attitudes around GHWL may allow better implementation of future public health policies. Singapore introduced GHWL in 2004, five years before they were introduced in the UK; this study aims to investigate any potential desensitisation effect by direct comparison.

Methods Data were collected from 266 smokers and non-smokers, 163 from London $(54.6 \%$ smokers, $54.0 \%$ male, mean age $52.4(17.8)$ ) and 103 from Singapore (47.6\% smokers, $77.7 \%$ male, mean age 57.7 (14.5)) between 2011 and 2013. A structured interview with fifty items, showing ten different GHWL, recorded demographics, smoking history, plans to quit and knowledge about the health-related consequences of smoking, as well as the emotional response, processing and impact of GHWL on behaviour. Participants further ranked hypothetical conditions that they could develop in terms of prevention and treatment.

Results The London cohort experienced significantly higher levels of 'disgust' when viewing GHWL than their Singapore counterparts (smokers $74.1 \%$ vs $49.0 \%, p=0.003$; non-smokers $83.8 \%$ vs $57.4 \%, \mathrm{p}<0.001)$, and felt GHWLs were a sufficient deterrent (smokers $33.7 \%$ vs $16.3 \%, p=0.029$; non-smokers $71.6 \%$ vs $50.0 \%, \mathrm{p}=0.013$ ). London non-smokers had a higher awareness of heart disease $(82.4 \%$ vs $32.0 \%, \mathrm{p}=0.007)$, stroke $(72.3 \%$ vs $28.2 \%, p=0.02)$, mouth and throat cancer $(95.6 \%$ vs $35.0 \%, \mathrm{p}<0.001)$ and lung cancer $(98.7 \%$ vs $35.0 \%$, p < 0.001 ) as smoking-related diseases. London smokers reported an increased motivation to quit if they hypothetically developed smoking-related disease $(85.2 \%$ vs $72.7 \%, \mathrm{p}=0.001)$. Blindness was the least well-known consequence overall (27.8\%), despite provoking the highest levels of fear amongst Singaporeans.

Conclusion A desensitisation effect of GHWL is observed in cohorts with an increased length of exposure, both in smokers 